\title{
Necrotizing Fasciitis and Sepsis Caused by Vibrio vulnificus and Klebsiella pneumoniae in Diabetic Patients
}

\author{
Jiun-Cheng Hsu, Shih-Hsun Shen, Tien-Yu Yang, Po-Han Chen, Kuo-Chin Huang, Yao-Hung Tsai
}

Background: Vibrio vulnificus related necrotizing fasciitis is a fatal, rapidly progressive soft-tissue infection. Necrotizing fasciitis caused by Klebsiella pneumoniae is rare, which is indistinguishable from $V$. vulnificus infection in the emergency room. The purpose of this study was to compare the clinical characteristics and outcome between these two pathogens in diabetic patients.

Methods: Thirty diabetic patients were retrospectively reviewed over an 8-year period. Necrotizing fasciitis caused by $V$. vulnificus was found in 19 patients and by $K$. pneumoniae in 11 patients. The demographic, clinical, and laboratory characteristics, and the outcome between diabetic patients with $V$. vulnificus and $K$. pneumoniae infections were compared.

Results: $\quad$ Two patients in the V. vulnificus group (10.5\%) and three patients in the K. pneumoniae group $(27.3 \%)$ died. Fourteen patients in the $V$. vulnificus group (73.6\%) had a history of

\section{At a Glance Commentary \\ Scientific background of the subject}

The purpose of this study was to compare the specific characteristics and clinical outcomes between $V$. vulnificus and K. pneumoniae necrotizing fasciitis.

\section{What this study adds to the field}

V. vulnificus infection progresses more rapidly than $K$. pneumoniae infection during the initial clinical course. The contact history and severity of symptoms should alert clinicians to distinguish between $V$. vulnificus and $K$. pneumoniae infections in diabetic patients with necrotizing fasciitis. exposure to seawater or raw seafood, and eight patients in the K. pneumoniae group (72.8\%) had abrasions or chronic ulcers over the site of infection. We found that the time interval between onset of illness and presentation to the hospital was significantly shorter in the $V$. vulnificus group than in the $K$. pneumoniae group ( 2.47 days vs. 5.45 days, $p<0.001)$.

Conclusions: The exposure history and the time from exposure to hospital presentation with severe sepsis syndromes should alert clinicians to distinguish between necrotizing soft-tissue infections with $V$. vulnificus (contact with seawater or raw seafood) and K. pneumoniae (abrasions or chronic ulcers) in diabetic patients. Infection with $V$. vulnificus progresses more rapidly than infection with K. pneumoniae during the initial clinical course.

(Biomed J 2015;38:136-142)

Key words: klebsiella pneumonia, necrotizing fasciitis, Vibrio vulnificus

$\mathrm{N}$ ecrotizing fasciitis is a life-threatening soft-tissue infection with a high mortality rate, which requires emergent surgical debridement and broad-spectrum antibiotic treatment when the diagnosis is confirmed. The clinical features of necrotizing fasciitis include rapidly progressive skin necrosis with subcutaneous tissue and deep fascia involvement, and result in sepsis and multi-organ failure..$^{[1-4]}$ Early diagnosis of necrotizing fasciitis is essential for treatment; however, necrotizing fasciitis is often indistinguishable from cellulitis due to the non-specific symptoms and signs on initial presentation in the emergency room. ${ }^{[1-5]}$ Necrotizing fasciitis and progressive sepsis occur more frequently in patients with hepatic disease, diabetes mellitus, and adrenal insufficiency, and in patients who are immunocom-

From the Department of Orthopaedic Surgery, Chang Gung Memorial Hospital at Chiayi, Chang Gung University, College of Medicine, Taoyuan, Taiwan

Received: Mar. 04, 2014; Accepted: Jun. 27, 2014

Correspondence to: Dr. Yao-Hung Tsai, Department of Orthopaedic Surgery, Chang Gung Memorial Hospital at Chiayi. 6, West Sec, Chia-Pu Rd. Putz City, Chiayi, 613, Taiwan (ROC). Tel: 886-5-3621000; ext. 2885; Fax: 886-5-3623005; E-mail: orma2244@adm.cgmh.org.tw

DOI: $10.4103 / 2319-4170.137767$ 
promised..$^{[4-6]}$ Angoules ${ }^{[4]}$ conducted a systematic review of necrotizing fasciitis, and the predominant underlying disease leading to the development of necrotizing fasciitis was found to be diabetes mellitus ( $31 \%)$.

We previously reported that the clinical characteristics of gram-negative necrotizing soft-tissue infections are more rapidly progressive and fulminant than gram-positive infections. ${ }^{[7]}$ Vibrio species are found to be the predominant clinical pathogens that cause necrotizing fasciitis and septicemia in the patients seen in our institution, especially in the summer season, in association with minor trauma and exposure to fish or seawater. Necrotizing fasciitis caused by Klebsiella pneumoniae, however, had the highest mortality rate $(60 \%)$ and all of the patients had diabetes mellitus. ${ }^{[7]}$

$K$. pneumoniae is a common bacterial pathogen for urinary tract infections, pneumonia, and bacteremia. It is also known to cause liver abscesses and necrotizing fasciitis among patients in eastern Asia ${ }^{[5]}$ Necrotizing fasciitis caused by $K$. pneumoniae is uncommon, and is strongly associated with predisposing conditions such as diabetes mellitus. The occurrence of necrotizing fasciitis caused by K. pneumoniae in Western countries is rare, and few cases have been reported. ${ }^{[8-10]}$ The clinical manifestations of necrotizing fasciitis caused by K. pneumoniae and Vibrio vulnificus are similar, which include ecchymoses, hemorrhagic bullae, tissue necrosis, and gangrene over the site of infection.

The purpose of this study was to compare the clinical, laboratory features and outcomes of necrotizing fasciitis caused by V. vulnificus and K. pneumoniae in diabetic patients.

\section{METHODS}

Our institution is situated in the western coast of southern Taiwan and has a 1000-bed capacity. We retrospectively reviewed the medical records of 30 diabetic patients with necrotizing fasciitis between 2005 and 2012. Data on the causal microorganisms were determined by reviewing the microbiological reports of wound and/or blood culture samples that were taken before or at the time of operation. The diagnosis of necrotizing fasciitis was based on intraoperative and histopathologic findings.

Data on the demographic, clinical, laboratory, preceding local factors (including skin ulcer, and any other identified local factors or events that occurred over the site of infection), site of necrotizing fasciitis, local findings of infection site, time lapses between illness onset and hospital presentation, time lapses between necrotizing fasciitis diagnosis and surgical intervention, length of hospital stay, and outcome were collected for analyses. The included diabetic patients were divided into the following groups for further analyses: Patients with $V$. vulnificus infection and patients with $K$. pneumoniae infection.

Statistical analyses were performed with SPSS (version 12.0; SPSS, Inc., Chicago, IL, USA). Variables in $V$. vulnificus group and K. pneumoniae group were compared with each other using univariate analyses. In univariate analysis, the Wilcoxon rank-sum test was used for comparison of continuous variables, whereas the Fisher exact test was used for comparison of categorical variables. The $p<0.05$ were considered significant. This retrospective study was approved by the Ethics Committee and institutional review board of Chang Gung Memorial Hospital (98-0325C).

\section{RESULTS}

The clinical and laboratory characteristics of 19 diabetic patients with $V$. vulnificus necrotizing fasciitis are summarized in Table 1 . The $V$. vulnificus group consisted of 16 men and 3 women, with a mean age of 64 years (range, 39-81 years). Eight patients had diabetes mellitus without co-existing diseases. Of the 11 diabetic patients with other comorbidities, 7 patients had chronic liver disease, 2 had adrenal insufficiency due to prior corticosteroid use, and 2 had gout. Among the seven diabetic patients with chronic liver disease, hepatitis B related liver cirrhosis was found in two patients, and hepatitis $\mathrm{C}$ related liver cirrhosis, hepatitis B related liver disease, hepatitis $\mathrm{C}$ related liver disease, hepatocellular carcinoma and hepatitis B, and liver cirrhosis of unknown cause were found in one patient each.

Among the 19 diabetic patients with $V$ vulnificus infection, lower limb involvement was found in 9 patients and upper limb involvement in 10 patients [Figure 1]. The mean time from onset of illness to hospital presentation was 2.47 days (range, $1-4$ days). All the patients in this group underwent fasciotomy initially; however, one patient had an above-the-knee amputation due to progressive infection and uncontrolled sepsis after fasciotomy. The mean duration of hospitalization was 34.4 days (range, 8-61 days). Five patients (26\%) experienced hypotension in the emergency room. Fever was found in $7(36 \%)$ patients when they presented to emergency room. $V$. vulnificus isolates were susceptible to ampicillin, amikacin, ceftazidime, ceftriaxone, cefuroxime, ciprofloxacin, gentamicin, imipenem, piperacillin, and sulfamethoxazole-trimethoprim. Broad-spectrum antibiotics were administered initially in the emergency room to patients with $V$. vulnificus infection; ceftriaxone alone was given in nine, ceftriaxone plus tetracycline in five, ceftriaxone plus gentamicin in three, and oxacillin plus gentamicin in two. The bacteremia rate was $47 \%$, and the mortality rate in this $V$. vulnificus group was $10 \%(2 / 19)$.

The clinical and laboratory characteristics of 11 patients with $K$. pneumoniae necrotizing fasciitis are summarized in Table 2. The $K$. pneumoniae group consisted of 8 men and 3 women, with a mean age of 61.5 years (range, 40-90 years). One patient had diabetes mellitus without a co-existing disease. Of 10 diabetic patients with other co- 
Table 1: Characteristics and laboratory data of Vibrio vulnificus patients

\begin{tabular}{|c|c|c|c|c|c|c|c|c|c|c|c|c|c|}
\hline Patient & $\begin{array}{c}\text { Age } \\
\text { (years) }\end{array}$ & Gender & $\begin{array}{l}\text { Chronic } \\
\text { underlying } \\
\text { disease }\end{array}$ & $\begin{array}{l}\text { Site of } \\
\text { infection }\end{array}$ & $\begin{array}{c}\text { Interval } \\
\text { A } \\
\text { (days) }\end{array}$ & $\begin{array}{l}\text { Preceding } \\
\text { local } \\
\text { factors }\end{array}$ & $\begin{array}{c}\text { Interval } \\
\text { B } \\
\text { (hours) }\end{array}$ & $\begin{array}{l}\text { Operations } \\
\text { (first, final) }\end{array}$ & Outcome & $\begin{array}{c}\text { Duration of } \\
\text { hospitalization } \\
\text { (days) }\end{array}$ & $\begin{array}{c}\mathrm{HbA1c} \\
(\%)\end{array}$ & $\begin{array}{l}\text { Intensive } \\
\text { care unit } \\
\text { stay }\end{array}$ & $\begin{array}{l}\text { Positive } \\
\text { culture }\end{array}$ \\
\hline 1 & 76 & $\mathrm{~F}$ & $\begin{array}{l}\mathrm{HCC}, \\
\mathrm{DM}, \mathrm{HB}\end{array}$ & Right leg & 1 & Abrasion & 6 & Fas, AK & Death & 17 & $\mathrm{~N}$ & $\mathrm{Y}$ & B and W \\
\hline 2 & 64 & $\mathrm{~F}$ & LC, DM & $\begin{array}{l}\text { Both } \\
\text { hands }\end{array}$ & 4 & Fish & 4 & Fas & Death & 61 & $\mathrm{~N}$ & $\mathrm{Y}$ & W \\
\hline 3 & 53 & M & $\mathrm{DM}$ & Right arm & 2 & Fish & 2 & Fas, STSG & Survival & 46 & $\mathrm{~N}$ & Y & $\mathrm{W}$ and $\mathrm{B}$ \\
\hline 4 & 70 & M & $\mathrm{DM}$ & Right leg & 2 & Fish & 16 & Fas, flap & Survival & 45 & 13 & Y & W \\
\hline 5 & 67 & M & $\mathrm{HC}, \mathrm{DM}$ & Right arm & 1 & Oyster & 2 & Fas, debride & Survival & 56 & $\mathrm{~N}$ & $\mathrm{~N}$ & W \\
\hline 6 & 64 & M & $\begin{array}{l}\text { HB, DM, } \\
\text { gout }\end{array}$ & $\begin{array}{l}\text { Left } \\
\text { forearm }\end{array}$ & 2 & Fish & 4 & Fas, STSG & Survival & 40 & 6.7 & $\mathrm{~N}$ & $\mathrm{~W}$ and $\mathrm{B}$ \\
\hline 7 & 38 & M & $\begin{array}{l}\mathrm{DM}, \mathrm{LC}, \\
\mathrm{HB}\end{array}$ & Left leg & 3 & Seawater & 3 & Fas, STSG & Survival & 60 & $\mathrm{~N}$ & Y & $\mathrm{B}$ and $\mathrm{W}$ \\
\hline 8 & 74 & M & DM, gout & Left hand & 2 & Seafood & 2 & Fas, debride & Survival & 26 & 7.8 & Y & $\mathrm{B}$ and $\mathrm{W}$ \\
\hline 9 & 72 & M & $\begin{array}{l}\mathrm{DM}, \\
\text { steroid }\end{array}$ & Right leg & 2 & Seawater & 2 & Fas, STSG & Survival & 30 & $\mathrm{~N}$ & $\mathrm{Y}$ & $\mathrm{W}$ and $\mathrm{B}$ \\
\hline 10 & 70 & M & $\mathrm{DM}$ & $\begin{array}{l}\text { Both } \\
\text { hands }\end{array}$ & 3 & Seawater & 2 & Fas, STSG & Survival & 40 & $\mathrm{~N}$ & Y & W \\
\hline 11 & 57 & M & DM, gout & Left leg & 4 & Fish & 5 & Fas, STSG & Survival & 23 & 6.1 & $\mathrm{~N}$ & W \\
\hline 12 & 78 & $\mathrm{~F}$ & $\mathrm{DM}$ & Left leg & 2 & Fish & 2 & Fas, flap & Survival & 33 & $\mathrm{~N}$ & Y & W \\
\hline 13 & 81 & M & $\mathrm{DM}$ & Left hand & 4 & Fish & 12 & Fas, debride & Survival & 18 & 6.2 & $\mathrm{~N}$ & $\mathrm{~W}$ \\
\hline 14 & 58 & M & $\begin{array}{l}\mathrm{HC}, \mathrm{LC}, \\
\mathrm{DM}\end{array}$ & Right leg & 1 & Oyster & 2 & Fas, debride & Survival & 12 & 6.9 & $\mathrm{Y}$ & $\mathrm{W}$ and $\mathrm{B}$ \\
\hline 15 & 67 & $\mathrm{M}$ & $\begin{array}{l}\mathrm{DM}, \\
\text { steroid }\end{array}$ & Left hand & 2 & Seawater & 3 & Fas, STSG & Survival & 31 & $\mathrm{~N}$ & Y & W \\
\hline 16 & 57 & M & $\mathrm{DM}$ & Right leg & 3 & Farm & 2 & Fas, debride & Survival & 8 & $\mathrm{~N}$ & Y & B \\
\hline 17 & 75 & $\mathrm{M}$ & $\mathrm{DM}$ & Right leg & 4 & Farm & 10 & Fas, STSG & Survival & 42 & $\mathrm{~N}$ & $\mathrm{Y}$ & B and $\mathrm{W}$ \\
\hline 18 & 68 & M & $\mathrm{DM}$ & $\begin{array}{l}\text { Right } \\
\text { forearm }\end{array}$ & 1 & $\begin{array}{l}\text { Spider } \\
\text { bite }\end{array}$ & 1 & Fas, STSG & Survival & 31 & 7.5 & $\mathrm{~N}$ & W \\
\hline 19 & 54 & M & $\begin{array}{l}\mathrm{DM}, \mathrm{LC}, \\
\mathrm{HB}\end{array}$ & Right leg & 4 & Unknown & 2 & Fas, STSG & Survival & 35 & 9.1 & $\mathrm{Y}$ & B and $\mathrm{W}$ \\
\hline
\end{tabular}

Abbreviations: HC: Hepatitis C; HCC: Hepatic cell carcinoma; LC: Liver cirrhosis; HB, Hepatitis B; DM: Diabetes mellitus; Interval A: Time from onset of illness to presentation to hospital; Interval B: Time interval between diagnosis and surgical intervention; Fas: Fasciotomy; AK: Above-the-knee amputation; STSG: Split-thickness skin graft; M: Male; F: Female; B: Blood; W: Wound.

morbidities, 5 patients had chronic liver disease, 1 had gout and adrenal insufficiency, 1 had adrenal insufficiency, 1 had a history of myocardial infarction, 1 had alcoholic liver disease, and 1 had a history of stroke and gout. Among the five diabetic patients with chronic liver disease, hepatitis $\mathrm{C}$ related liver cirrhosis was found in two patients, and hepatitis B related liver disease, hepatitis $\mathrm{C}$ related liver disease, and liver cirrhosis of unknown cause were found in one each.

Of the 11 diabetic patients with $K$. pneumoniae infection, polymicrobial infection was found in 2 patients. Other pathogens which were identified in polymicrobial infections were Enterobacter cloacae and Group B streptococcus in Case 9 and Serratia marcescens in Case 10 [Table 2]. Three of the patients had upper limb involvement and eight patients had lower limb involvement [Figure 2]. The mean time from onset of illness to hospital presentation was 5.45 days (range, 2-12 days). Nine patients in this group initially underwent fasciotomies and two patients had above-the-knee amputations. The mean duration of hospital- ization was 26.8 days (range, 8-60 days). Four patients (36\%) experienced hypotension at presentation to the hospital. Only one (9\%) patient with $K$. pneumoniae necrotizing fasciitis was found to have fever at presentation to the hospital. K. pneumoniae isolates were susceptible to amikacin, ceftazidime, ceftriaxone, cefuroxime, ciprofloxacin, aztreonam, gentamicin, and imipenem. Broad-spectrum antibiotics were administered initially in the emergency room to patients with $K$. pneumoniae infection; ceftriaxone alone was given in five, cefazolin plus gentamicin in two, ceftriaxone plus gentamicin in two, and ceftriaxone plus vancomycin in two patients. The bacteremia rate was $18 \%$, and the mortality rate in the K. pneumoniae group was $27 \%(3 / 11)$.

There was no difference in the demographic characteristics, underlying conditions, laboratory data, site(s) of necrotizing fasciitis, local findings of infection site, time lapses between necrotizing fasciitis diagnosis and surgical intervention, duration of hospital stay, and mortality rate between the two groups [Tables 3 and 4]. There were no concomitant 
Table 2: Characteristics and laboratory data of Klebsiella pneumoniae patients

\begin{tabular}{|c|c|c|c|c|c|c|c|c|c|c|c|c|c|}
\hline Patient & $\begin{array}{l}\text { Age } \\
\text { (years) }\end{array}$ & Gender & $\begin{array}{l}\text { Chronic } \\
\text { underlying } \\
\text { disease }\end{array}$ & $\begin{array}{l}\text { Site of } \\
\text { infection }\end{array}$ & $\begin{array}{c}\text { Interval } \\
\text { A } \\
\text { (days) }\end{array}$ & $\begin{array}{l}\text { Preceding } \\
\text { local } \\
\text { factors }\end{array}$ & $\begin{array}{c}\text { Interval } \\
\text { B } \\
\text { (hours) }\end{array}$ & $\begin{array}{l}\text { Operations } \\
\text { (first, final) }\end{array}$ & Outcome & $\begin{array}{c}\text { Duration of } \\
\text { hospitalization } \\
\text { (days) }\end{array}$ & $\begin{array}{c}\mathrm{HbA1c} \\
(\%)\end{array}$ & $\begin{array}{l}\text { Intensive } \\
\text { care unit } \\
\text { stay }\end{array}$ & $\begin{array}{l}\text { Positive } \\
\text { culture }\end{array}$ \\
\hline 1 & 84 & $\mathrm{M}$ & DM, old MI & $\begin{array}{l}\text { Right } \\
\text { forearm }\end{array}$ & 7 & Unknown & 5 & Fas & Death & 8 & 9 & $\mathrm{Y}$ & $\mathrm{W}$ \\
\hline 2 & 90 & F & $\begin{array}{l}\text { DM, gout, } \\
\text { steroid }\end{array}$ & Left leg & 2 & Abrasion & 3 & $\begin{array}{l}\text { AK, } \\
\text { debride }\end{array}$ & Death & 16 & 10.8 & Y & W \\
\hline 3 & 58 & M & DM, steroid & Left leg & 4 & Abrasion & 7 & $\begin{array}{l}\text { Fas, } \\
\text { debride }\end{array}$ & Death & 59 & $\mathrm{~N}$ & Y & $\mathrm{B}$ and $\mathrm{W}$ \\
\hline 4 & 49 & M & $\mathrm{DM}, \mathrm{LC}, \mathrm{HC}$ & Right leg & 7 & Seawater & 12 & Fas, STSG & Survival & 44 & $\mathrm{~N}$ & $\mathrm{Y}$ & B and W \\
\hline 5 & 55 & M & $\begin{array}{l}\text { DM, HC, } \\
\text { gout }\end{array}$ & $\begin{array}{l}\text { Right } \\
\text { arm }\end{array}$ & 6 & Abrasion & 6 & Fas, STSG & Survival & 26 & 8.3 & $\mathrm{Y}$ & W \\
\hline 6 & 43 & M & DM, & Left leg & 7 & $\begin{array}{l}\text { Chronic } \\
\text { ulcer }\end{array}$ & 5 & $\begin{array}{l}\text { Fas, } \\
\text { debride }\end{array}$ & Survival & 10 & 8 & $\mathrm{Y}$ & W \\
\hline 7 & 77 & F & $\mathrm{DM}, \mathrm{LC}, \mathrm{HC}$ & Left leg & 7 & Abrasion & 2 & Fas, STSG & Survival & 60 & $\mathrm{~N}$ & $\mathrm{~N}$ & W \\
\hline 8 & 82 & F & $\begin{array}{l}\text { DM, stroke, } \\
\text { gout }\end{array}$ & Left leg & 3 & Ulcer & 6 & $\mathrm{AK}$ & Survival & 16 & 9.1 & $\mathrm{Y}$ & W \\
\hline 9 & 48 & M & $\mathrm{DM}, \mathrm{HB}$ & Left leg & 2 & Cutting & 18 & Fas, STSG & Survival & 22 & 7.3 & $\mathrm{~N}$ & W \\
\hline 10 & 51 & M & $\begin{array}{l}\text { DM, } \\
\text { alcoholism }\end{array}$ & $\begin{array}{l}\text { Right } \\
\text { foot }\end{array}$ & 12 & $\begin{array}{l}\text { Nail } \\
\text { injury }\end{array}$ & 5 & Fas & Survival & 13 & 7.2 & $\mathrm{~N}$ & W \\
\hline 11 & 40 & M & DM, LC & $\begin{array}{l}\text { Right } \\
\text { forearm }\end{array}$ & 3 & Unknown & 14 & Fas, STSG & Survival & 21 & 13 & $\mathrm{~N}$ & W \\
\hline
\end{tabular}

Abbreviations: DM: Diabetes mellitus; MI: Myocardial infarction; LC: Liver cirrhosis; HB, Hepatitis B; HC: Hepatitis C; Interval A: Time from onset of illness to hospital presentation; Interval B: Time interval between diagnosis and surgical intervention; Fas: Fasciotomy; AK: Above-the-knee amputation; STSG: Split-thickness skin graft; M: Male; F: Female; B: Blood; W: Wound.

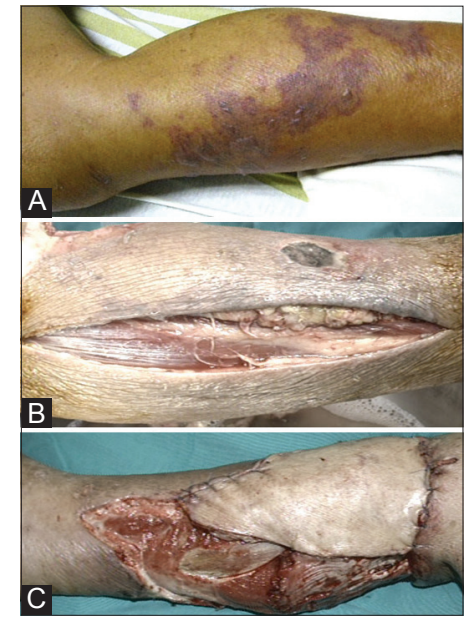

Figure 1: A 70-year-old fisherman with a history of diabetes mellitus had right low leg swollen with pain on the second day after contact with raw fish. (A) Preoperative photographs of the right low leg revealed purpura and subcutaneous bleeding. (B) After emergency fasciotomy, the right low leg revealed a dishwater-colored fluid seeping from the wound. A wound culture confirmed the presence of Vibrio vulnificus. (C) He underwent microvascular flap surgery on the $21^{\text {st }}$ day after admission and was discharged on the $45^{\text {th }}$ day.

distant abscesses and metastatic infections involving other organs, such as brain, lung, and liver abscess, in both the groups. In contrast, a significant difference existed between the two groups with respect to the time interval between onset of illness and presentation to the hospital $(p<0.001)$. The average time from the onset of illness to presentation to

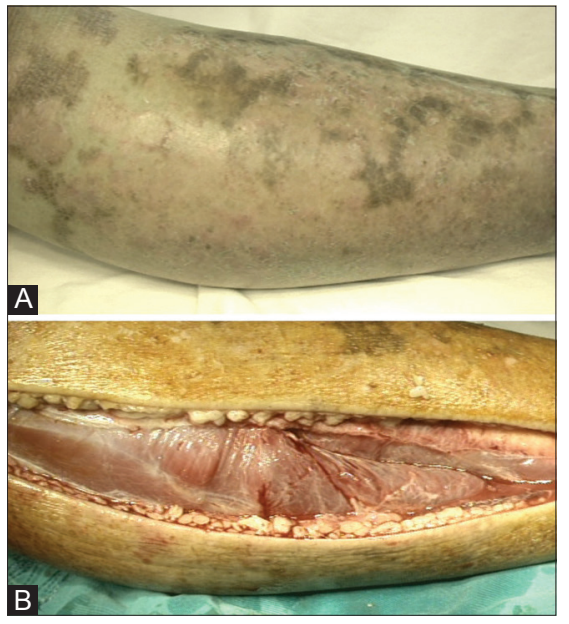

Figure 2: A 49-year-old male with a history of diabetes mellitus and liver cirrhosis with hepatitis $\mathrm{C}$ had gradual pain in right low leg for 7 days. (A) The right low leg revealed patchy purpura and edema in the emergency room. (B) Twelve hours later, he was sent to operation room for emergency fasciotomy. The wound showed turbid fluid accumulated in the subcutaneous area and fascia with dark-colored muscles. The cultured specimen confirmed Klebsiella pneumoniae. This patient received debridement and skin graft, and was discharged on the $44^{\text {th }}$ day after admission.

the hospital in the $V$. vulnificus group was shorter than that in the K. pneumoniae group (mean duration, $2.47 \pm 1.12$ days vs. $5.45 \pm 3.01$ days).

When compared to K. pneumoniae group, patients in $V$. vulnificus group had a significantly higher frequency 
Table 3: Comparison of demographic data, clinical data, symptom/signs, and outcome between Vibrio vulnificus and Klebsiella pneumoniae infections in diabetic patients

\begin{tabular}{|c|c|c|c|}
\hline Variable & $\begin{array}{c}\text { Vibrio } \\
\text { vulnificus } \\
\text { group }(n=19)\end{array}$ & $\begin{array}{c}\text { Klebsiella } \\
\text { pneumoniae } \\
\text { group }(n=11)\end{array}$ & $p$ value \\
\hline Age (years) (mean \pm SD) & $65.4 \pm 10.6$ & $61.5 \pm 18.0$ & 0.20 \\
\hline Male, $n(\%)$ & $16(84)$ & $8(73)$ & 0.27 \\
\hline Mortality rate, $n(\%)$ & $2(10.5)$ & $3(27.2)$ & 0.19 \\
\hline $\begin{array}{l}\text { Time interval from the onset } \\
\text { of illness to arrival at hospital } \\
\text { (days) (mean } \pm \text { SD) }\end{array}$ & $2.47 \pm 1.12$ & $5.45 \pm 3.01$ & $<0.001$ \\
\hline $\begin{array}{l}\text { Time lapses between NF } \\
\text { diagnosis and surgical } \\
\text { intervention (hours) (mean } \pm \mathrm{SD})\end{array}$ & $4.31 \pm 4.04$ & $7.54 \pm 4.97$ & 0.06 \\
\hline \multicolumn{4}{|l|}{ Underlying disease, $n(\%)$} \\
\hline Chronic liver disease & $7(36.8)$ & $6(54.5)$ & 0.194 \\
\hline Gout & $2(10.5)$ & $1(9.1)$ & 0.702 \\
\hline Adrenal insufficiency & $2(10.5)$ & $1(9.1)$ & 0.702 \\
\hline $\begin{array}{l}\text { Gout and adrenal } \\
\text { insufficiency }\end{array}$ & 0 & $1(9.1)$ & 0.367 \\
\hline Old MI & 0 & $1(9.1)$ & 0.367 \\
\hline \multicolumn{4}{|l|}{ Local inflammation signs, $n(\%)$} \\
\hline Crepitation & $0(0)$ & $2(18)$ & 0.12 \\
\hline Bullous lesion & $12(63.2)$ & $5(45.4)$ & 0.19 \\
\hline \multicolumn{4}{|l|}{ Preceding factors, $n(\%)$} \\
\hline $\begin{array}{l}\text { Exposure to seawater or } \\
\text { consumption of raw seafood }\end{array}$ & $14(73.6)$ & $1(9)$ & 0.003 \\
\hline Abrasion or chronic ulcers & $1(5.3)$ & $8(72.8)$ & $<0.001$ \\
\hline Site of infection, $n(\%)$ & & & 0.24 \\
\hline Upper extremity & $9(47.4)$ & $3(27.3)$ & \\
\hline Lower extremity & $10(52.6)$ & $8(72.7)$ & \\
\hline $\begin{array}{l}\text { Mean length of hospital } \\
\text { stay (days) }\end{array}$ & $34.4 \pm 15.3$ & $26.8 \pm 16.2$ & 0.32 \\
\hline
\end{tabular}

Abbreviations: DM: Diabetes mellitus; MI: Myocardial infarction; NF: Necrotizing fasciitis; SD: Standard deviation

Table 4: Comparison of the initial laboratory data between Vibrio vulnificus and Klebsiella pneumoniae infections in diabetic patients

\begin{tabular}{|c|c|c|c|}
\hline & $\begin{array}{l}\text { Vibrio vulnificus } \\
\text { group }(n=19)\end{array}$ & $\begin{array}{c}\text { Klebsiella } \\
\text { pneumoniae } \\
\text { group }(n=11)\end{array}$ & $p$ value \\
\hline $\begin{array}{l}\text { Mean white blood cell } \\
\text { count }\left(\text { cells } / \mathrm{mm}^{3}\right) \pm \mathrm{SD}\end{array}$ & $13,689.5 \pm 5509$ & $17,045.5 \pm 9876$ & 0.24 \\
\hline $\begin{array}{l}\text { Mean band } \\
\text { neutrophil }(\%) \pm \mathrm{SD}\end{array}$ & $7.89 \pm 7.12$ & $4.64 \pm 5.73$ & 0.21 \\
\hline $\begin{array}{l}\text { Mean segmented } \\
\text { neutrophil }(\%) \pm \mathrm{SD}\end{array}$ & $77.88 \pm 8.47$ & $78.23 \pm 18.9$ & 0.95 \\
\hline $\begin{array}{l}\text { Mean } \\
\text { lymphocyte }(\%) \pm \mathrm{SD}\end{array}$ & $7.18 \pm 4.33$ & $9.95 \pm 7.32$ & 0.20 \\
\hline $\begin{array}{l}\text { Mean platelet count } \\
\left(\text { per } \mathrm{mm}^{3}\right) \pm \mathrm{SD}\end{array}$ & $128578.9 \pm 58390$ & $169909 \pm 79900$ & 0.11 \\
\hline Mean albumin $(\mathrm{g} / \mathrm{dl}) \pm \mathrm{SD}$ & $2.49 \pm 0.53$ & $2.12 \pm 0.51$ & 0.07 \\
\hline $\begin{array}{l}\text { Mean creatinine } \\
(\mu \mathrm{mol} / \mathrm{l}) \pm \mathrm{SD}\end{array}$ & $1.63 \pm 0.84$ & $1.35 \pm 0.59$ & 0.35 \\
\hline $\begin{array}{l}\text { Mean C-reactive } \\
\text { protein }(\mathrm{mg} / \mathrm{l}) \pm \mathrm{SD}\end{array}$ & $98.9 \pm 109$ & $144.8 \pm 101$ & 0.26 \\
\hline
\end{tabular}

Abbreviation: SD: Standard deviation of exposure to seawater or consumption of raw seafood (73.6\% vs. 9\%; $p=0.003)$ and lower frequency of abrasions or chronic ulcers (5.3\% vs. $72.8 \% ; p<0.001)$.

\section{DISCUSSION}

Diabetes mellitus is an important predisposing illness that affects the progression and severity of necrotizing fasciitis based on peripheral vaso-occlusion and "sugar-coated capillaries" limiting the blood supply to superficial and deep structures. ${ }^{[2,4,11,12]}$ Untreated tissues will become gangrenous in several days, and subsequent invasion of the bloodstream by virulence factors released from the gangrenous tissues can easily cause fulminant sepsis and possible death in diabetic patients with necrotizing fasciitis. ${ }^{[11,2]}$

$V$. vulnificus is a gram-negative marine bacterium that is usually present in warm coastal waters. The main clinical manifestations of $V$. vulnificus infections in humans are gastrointestinal illnesses, primary septicemia, and wound infections. The clinical course can progress rapidly by releasing hemolysins and proteases, and result in hemorrhagic bullae and severe skin necrosis. ${ }^{[13-16]}$ The routes of necrotizing fasciitis caused by $V$. vulnificus include wound infections while handling seafood, exposure of a pre-existing wound to seawater, and ingestion of contaminated undercooked seafood. ${ }^{[13-16]}$

Necrotizing skin and soft-tissue infections caused by $K$. pneumoniae are often associated with liver abscesses and diabetes mellitus; specifically, diabetes mellitus was present in $62.5-100 \%$ of such patients. ${ }^{[10,17-21]} \mathrm{K}$. pneumoniae is a non-motile, rod-shaped, gram-negative bacterium with a prominent polysaccharide capsule. The polysaccharide capsule encases the entire cell surface and provides resistance against many host defense mechanisms. Capsule polysaccharides and lipopolysaccharides, such as $\mathrm{K} 1$ and $\mathrm{K} 2$, are the most virulent serotypes and important virulence factors of K. pneumoniae. ${ }^{[17,18,20,22]}$

Our previous studies showed that patients with hepatic dysfunction had significant associations with $V$. vulnificus infections; however, $V$. vulnificus can also produce severe sepsis in diabetic patients with or without other chronic illnesses. ${ }^{[14]}$ Necrotizing fasciitis caused by K. pneumoniae is extremely rare in the western hemisphere, but necrotizing fasciitis caused by $K$. pneumoniae has been increasingly reported in the past decade, with fatality rates approaching $50 \% .{ }^{[10,17-21]}$ In the current study, the mortality rates for diabetic patients in the $V$. vulnificus and $K$. pneumoniae groups were $10.5 \%$ and $27.2 \%$, respectively, after early surgical debridement and adequate antibiotic treatment. We considered that capsule polysaccharides and lipopolysaccharides of $K$. pneumoniae can cause more immunologic defect and severe infections in the hyperglycemic status than that 
caused by $V$. vulnificus. Thus, we recommend that diabetic patients with necrotizing fasciitis should be evaluated for K. pneumoniae infections initially until proven otherwise, due to the high mortality rate.

This study reveals two differences between $V$. vulnificus and K. pneumonia infections. First, the clinical manifestations and initial laboratory findings of necrotizing fasciitis caused by $V$. vulnificus and $K$. pneumoniae, which are gram-negative aerobic pathogens, are indistinguishable at the time of presentation. We found that the time interval from exposure to presentation in the emergency department for the $V$. vulnificus group (mean, 2.47 days) was significantly shorter than for the K. pneumoniae group (mean, 5.45 days). Thus, the initial clinical course of $V$. vulnificus infection is more rapidly progressive than that of $K$. pneumoniae infection. Further, hemolysins and proteases released by $V$. vulnificus may cause more rapid skin necrosis and severe sepsis than the polysaccharide capsule envelope of $K$. pneumoniae. Second, the contact mechanisms of the two pathogens differ. Most diabetic patients with $V$. vulnificus infections (73.6\%) had a history of contact with seawater or raw seafood, while the patients with $K$. pneumoniae infections (72.8\%) had chronic ulcers or wound abrasions.

Metastatic infections with $K$. pneumoniae necrotizing fasciitis, which may be a consequence of transient bacteremia, have been reported. ${ }^{[18-26]} \mathrm{Ho}$ et al. ${ }^{[19]}$ and Hu et al. ${ }^{[24]}$ have reported that patients with $K$. pneumoniae necrotizing fasciitis have concurrent liver abscesses. Dalal ${ }^{[26]}$ reported that patients with $K$. pneumoniae necrotizing fasciitis have associated lung abscesses. In the current study, no metastatic infections were noted in the K. pneumoniae group.

There were several limitations in this study. First, we had a small number of study cases. Second, we had missing data due to retrospective nature of the study. Third, we did not determine the capsular serotype of $K$. pneumoniae. Although genotype K1 strains are predominant in the East, we cannot fully understand the association between metastatic infections and bacteremia in necrotizing fasciitis without knowing the capsular serotype. Fourth, we did not determine the glycosylated hemoglobin (HbA1c) levels of all patients. Oncul et al. ${ }^{[27]}$ reported that a mean $\mathrm{HbA} 1 \mathrm{c}$ value of $10.6 \%$ was associated with poor prognosis and mortality. Two patients who died in the $K$. pneumoniae group had HbA1c values of $9 \%$ and $10.8 \%$, respectively. We should obtain the HbA1c values of diabetic patients to determine the association between elevated $\mathrm{HbA} 1 \mathrm{c}$ values and the prognostic factors for necrotizing fasciitis.

In conclusion, patients with diabetes mellitus should be aware of necrotizing fasciitis caused by $V$. vulnificus and $K$. pneumoniae, which is a true surgical emergency. The contact history and the time from exposure to presentation with severe symptoms should alert clinicians to distinguish necrotizing soft-tissue infections caused by V. vulnificus (contact with seawater or raw seafood) and K. pneumoniae (abrasions or chronic ulcers) in diabetic patients. V. vulnificus infections progress more rapidly than $K$. pneumoniae infections during the initial clinical course.

\section{REFERENCES}

1. Green RJ, Dafoe DC, Raffin TA. Necrotizing fasciitis. Chest 1996;110:219-29.

2. Wong CH, Chang HC, Pasupathy S, Khin LW, Tan JL, Low CO. Necrotizing fasciitis: Clinical presentation, microbiology, and determinants of mortality. J Bone Joint Surg Am 2003;85:1454-60.

3. Sarani B, Strong M, Pascual J, Schwab CW. Necrotizing fasciitis: Current concepts and review of the literature. J Am Coll Surg 2009;208:279-88.

4. Angoules AG, Kontakis G, Drakoulakis E, Vrentzos G, Granick MS, Giannoudis PV. Necrotizing fasciitis of upper and lower limb: A systematic review. Injury 2007;38 Suppl 5:18-25.

5. Sarani RS. Necrotizing fasciitis: Reviewing the causes and treatment strategies. Adv Skin Wound Care 2007;20:288-93.

6. Seal DV. Necrotizing fascitis. Curr Opin Infect Dis 2001;14:127-32.

7. Tsai YH, Huang KC, Shen SH, Hsu WH, Peng KT, Huang TJ. Microbiology and surgical indicators of necrotizing fasciitis in a tertiary hospital of southwest Taiwan. Int J Infect Dis 2012;16:e159-65.

8. Kelesidis T, Tsiodras S. Postirradiation Klebsiella pneumoniae-associated necrotizing fasciitis in the western hemisphere: Arare but life-threatening clinical entity. Am J Med Sci 2009;338:217-24.

9. Gunnarsson GL, Brandt PB, Gad D, Struve C, Justesen US. Monomicrobial necrotizing fasciitis in a white male caused by hypermucoviscous Klebsiella pneumoniae. J Med Microbiol 2009;58:1519-21.

10. Kohler JE, Hutchens MP, Sadow PM, Modi BP, Tavakkolizadeh A, Gates JD. Klebsiella pneumoniae necrotizing fasciitis and septic arthritis: An appearance in the Western hemisphere. Surg Infect (Larchmt) 2007;8:227-32.

11. Cunha BA. Skin and soft tissue infections in patients with diabetes mellitus. Infect Dis Clin Pract 1997;10:94-5.

12. Gurlek A, Firat C, Ozturk AE, Alaybeyoglu N, Fariz A, Aslan S. Management of necrotizing fasciitis in diabetic patients. J Diabetes Complications 2007;21:265-71.

13. Tsai YH, Hsu RW, Huang TJ, Hsu WH, Huang KC, Li YY, et al. Necrotizing soft tissue infections and sepsis caused by Vibrio vulnificus compared with those caused by Aeromonas species. J Bone Joint Surg Am 2007;89:631-6.

14. Tsai YH, Wen-Wen Hsu R, Hung KC, Huang TJ. The Comparison of Necrotizing Fasciitis and Sepsis Caused by Vibrio vulnificus and Staphylococcus aureus. J Bone Joint Surg Am 2011;93:274-84.

15. Chuang YC, Yuan CY, Liu CY, Lan CK, Huang AH. Vibrio vulnificus infection in Taiwan: Report of 28 cases and review of clinical manifestations and treatment. Clin Infect Dis 1992;15:271-6.

16. Zhang XH, Austin B. Haemolysins in Vibrio species. J Appl Microbiol 2005;98:1011-9.

17. Cheng NC, Yu YC, Tai HC, Hsueh PR, Chang SC, Lai SY, et al. Recent trend of necrotizing fasciitis in Taiwan: Focus on 
monomicrobial Klebsiella pneumoniae necrotizing fasciitis. Clin Infect Dis 2012;55:930-9.

18. Lee SS. Klebsiella pneumoniae is an emerging major pathogen in necrotizing fasciitis. Clin Infect Dis 2012;55:940-2.

19. Ho PL, Tang WM, Yuen KY. Klebsiella pneumoniae necrotizing fasciitis associated with diabetes and liver cirrhosis. Clin Infect Dis 2000;30:989-90.

20. Cortés G., Borrell N, de Astorza B, Gómez C, Sauleda J, Albertí S Molecular analysis of the contribution of the capsular polysaccharide and the lipopolysaccharide $\mathrm{O}$ side chain to the virulence of Klebsiella pneumoniae in a murine model of pneumonia. Infect Immun 2002;70:2583-90.

21. Wong CH, Kurup A, Wang YS, Heng KS, Tan KC. Four cases of necrotizing fasciitis caused by Klebsiella species. Eur J Clin Microbiol Infect Dis 2004;23:403-7.

22. Fung CP, Hu BS, Chang FY, Lee SC, Kuo BI, Ho M, et al. A 5-year study of the seroepidermiology of Klebsiella pneumoniae: High prevalence of capsular serotype K1 in Taiwan and implication for vaccine efficacy. J Infect Dis 2000;181:2075-9.
23. Fung CP, Chang FY, Lee SC, Hu BS, Kuo BI, Ho M, et al. A global emerging disease of Klebsellia pneumoniae liver abscess: Is serotype $\mathrm{K} 1$ an important factor for complicated endophthalmitis? Gut 2002;50:420-4.

24. Hu BS, Lau YJ, Shi ZY, Lin YH. Necrotizing fasciitis associated Klebsellia pneumoniae liver abscess. Clin Infect Dis 1999;29:1360-1.

25. Dyleski JS, Dylewski I. Necrotizing fasciitis with Klebsiella liver abscess. Clin Infect Dis 1998;27:1561-2.

26. Dalal M, Ahluwalia M, Urban C. Klebsiella pneumoniae necrotizing fasciitis associated with lung abscess. Infect Dis Clin Pract 2009; $17: 48-51$.

27. Oncul O, Erenoglu C, Top C, Kucukardali Y, Karabudak O, Kurt Y, et al. Necrotizing fasciitis: A life-threating clinical disorder in uncontrolled type 2 diabetic patients. Diabetes Res Clin Pract 2008;80:218-23. 